\title{
Inverse association between gastroesophageal reflux and blood pressure: Results of a large community based study

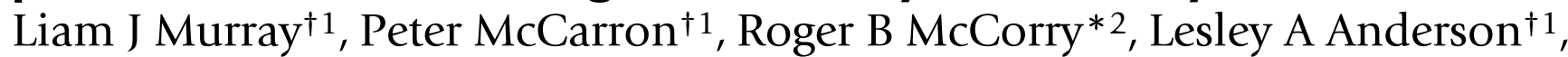 Athene J Lane ${ }^{\dagger 3}$, Brian T Johnston ${ }^{\dagger 4}$, George Davey Smith ${ }^{\dagger 3}$ and Richard F Harvey ${ }^{\dagger 5}$
}

\begin{abstract}
Address: ${ }^{1}$ Northern Ireland Cancer Registry, Department of Epidemiology and Public Health, The Queens University of Belfast, Belfast, UK, ${ }^{2}$ Bolton Hospitals NHS Trust, Bolton, UK, ${ }^{3}$ Department of Social Medicine, University of Bristol, Bristol, UK, ${ }^{4}$ Royal Hospitals Trust, Belfast, UK and ${ }^{5}$ Frenchay Hospital, North Bristol NHS Trust, Bristol, UK

Email: Liam J Murray - l.murray@qub.ac.uk; Peter McCarron - peter.mccarron@qub.ac.uk; Roger B McCorry* - rogermccorry@hotmail.com; Lesley A Anderson - l.anderson@qub.ac.uk; Athene J Lane - athene.lane@bristol.ac.uk; Brian T Johnston - Brian.Johnston@royalhospitals.ni.nhs.uk; George Davey Smith - George.Davey-Smith@bristol.ac.uk; Richard F Harvey - richard.harvey1@virgin.net

* Corresponding author †Equal contributors
\end{abstract}

Published: 15 April 2008

BMC Gastroenterology 2008, 8:10 doi:10.1186/1471-230X-8-10

This article is available from: http://www.biomedcentral.com/l47I-230X/8/10

(c) 2008 Murray et al; licensee BioMed Central Ltd.

This is an Open Access article distributed under the terms of the Creative Commons Attribution License (http://creativecommons.org/licenses/by/2.0), which permits unrestricted use, distribution, and reproduction in any medium, provided the original work is properly cited.
Received: 23 July 2007

Accepted: 15 April 2008

\begin{abstract}
Background: In a cross-sectional community based study, as part of a randomised controlled trial of eradication of Helicobacter pylori infection, the association between blood pressure and symptoms of gastro-oesophageal reflux was examined.

Methods: Linear regression was used to examine the association between systolic and diastolic blood pressure and the frequency of heartburn and acid regurgitation in 4,902 of 10,537 participants aged $20-59$ years.

Results: In multivariable analyses, adjusted mean systolic blood pressure was 4.2 (95\% confidence interval I.5 to 7.0$) \mathrm{mm} \mathrm{Hg}$ lower in participants with daily acid regurgitation compared to those with less frequent symptoms. Similarly, for diastolic blood pressure, a reduction of 2.1 ( 0.0 to 4.3 ) $\mathrm{mm} \mathrm{Hg}$ wasobserved.

Conclusion: People who experience daily symptoms of gastro-oesophageal reflux have lower blood pressure than people with less frequent or no symptoms. It is possible that factors influencing nitric oxide concentrations both at the lower oesophageal sphincter and within the vasculature may be involved. This hypothesis requires confirmation.
\end{abstract}

Trials registration number: ISRCTN448I6925

\section{Background}

In 2003 we reported reduced stroke mortality among patients with oesophageal columnar epithelium (Barrett's oesophagus), with cerebrovascular deaths in patients with specialised intestinal metaplasia of the oesophagus being half that of the general population [1]. Subsequently, a postmarketing surveillance study of 18,000 patients on omeprazole in the United Kingdom has not shown any reduction in stroke mortality in these patients compared to the general population [2] but this drug is often pre- 
scribed for upper gastrointestinal conditions other than gastro-oesophageal reflux and Barrett's oesophagus. We hypothesised that the association we observed may be due to individuals with reduced lower oesophageal sphincter (LOS) pressure, (a risk factor for gastro-oesophageal reflux and Barrett's oesophagus) also having low vascular tone and blood pressure, resulting in reduced stroke risk. To investigate this, we examined whether blood pressure is associated with symptoms of gastro-oesophageal reflux.

\section{Methods}

From 1996 to 1998, 10,537 individuals, aged 20-59 years, registered with seven general practices in Southwest England were enrolled in a community based randomised controlled trial of eradication of Helicobacter pylori $(H$. pylori). The trial obtained ethics approval from Frenchay Hospital LREC (reference number: 95/83 20/01/1996) and participants provided written informed consent. Participants provided information on the frequency of dyspeptic symptoms experienced in the previous three months, including heartburn ("a burning or ache behind the sternum not due to heart trouble") and acid regurgitation ("a very sour or acid tasting fluid at the back of the throat") using a validated questionnaire [3]. In addition, blood pressure, height, and weight were measured and data on antihypertensive medication, smoking history, alcohol and coffee consumption, and adult social class (derived from current occupation) were collected. The current analysis is based on all participants who tested positive for $H$. pylori infection $(\mathrm{n}=1,634)$ and a computer generated random sample of $H$. pylori negative participants $(\mathrm{n}=3,268)$ to give a $H$. pylori negative to positive ratio of $2: 1$

Linear regression was used to examine the association between systolic and diastolic blood pressure and the frequency of heartburn and acid regurgitation (daily vs. less frequent). Analyses took account of the clustered nature of the data (by general practice), and the increased sampling of $H$. pylori positive participants - 33\% of participants included in the database, but $15.5 \%$ of all participants screened - was dealt with by applying weights that were proportional to the inverse of the sampling fractions. Initial analyses were adjusted for age (years) and sex, while in fully-adjusted analyses we additionally controlled for body mass index (weight $(\mathrm{kg}) /$ height $^{2}(\mathrm{~m})$, smoking habit (never; ex-smoker; current smoker, $<20$ a day; current smoker $=20$ a day), weekly alcohol intake in units (none; $<10 ; 10-19 ;=20)$, daily coffee consumption in cups (none; $1-4 ;=5$ ) and adult social class (manual, non-manual). Similar analyses were conducted to examine whether the frequency of the occurrence of other dyspeptic symptoms (epigastric pain/discomfort, nausea, wind and belching) was associated with blood pressure. Since ageadjusted results were similar for the total sample and the
4,227 (86.2\%) individuals with data available on all confounders we report only the latter here. Analyses were carried out using Stata 7.0 (College Station, Texas, USA).

\section{Results}

One hundred and seven (2.5\%) and $66(1.6 \%)$ of the 4,227 participants with complete data experienced daily heartburn or acid regurgitation respectively. Participants experiencing either daily acid regurgitation or heartburn symptoms were heavier, and smoked more cigarettes than people with less frequent symptoms, while those with daily heartburn consumed more alcohol and were more likely to come from manual social class (Table 1). In age and sex-adjusted analyses, restricted to individuals not receiving antihypertensive medication (258 excluded), participants with daily acid regurgitation had lower mean systolic and diastolic blood pressure than individuals who had less frequent or no acid regurgitation (Table 2). Controlling for potential confounders strengthened these associations. There was no association between daily heartburn or the other dyspeptic symptoms and blood pressure.

\section{Discussion}

We found an inverse association between experiencing daily acid regurgitation and blood pressure. This was a large, population based study, whose participants were representative of the total sample. A wide age range of both sexes were studied producing novel findings. Weaknesses, however, include the fact the study was symptom based with no direct information regarding the underlying endoscopic diagnosis. Some researchers suggest that for heartburn a more complete 'word picture' than we used is required to avoid misreporting this symptom [4]. Misclassification may therefore have contributed to the weak relationship seen between blood pressure and heartburn. Moreover, as few participants in our study had daily reflux symptoms, our results need to be viewed as preliminary. However, there are several emerging strands of evidence to support a causal relationship between gastrooesophageal reflux and low blood pressure. Firstly, this finding is consistent with our previous observation of lower stroke mortality in patients with Barrett's oesophagus in a separate cohort from Northern Ireland [1]. Secondly, patients with gastro-oesophageal reflux disease have been shown to have decreased sympathetic function, with blunting of blood pressure responses to stress [5]. Thirdly, recent research into nitric oxide (NO) provides a mechanistic link between gastro-oesophageal reflux and low blood pressure. NO functions as the major nonadrenergic non-cholinergic neurotransmitter in the autonomic nervous system [6] and NO-mediated action appears to be crucial in governing LOS pressure [7]. Patients with gastro-oesophageal reflux have elevated levels of serum nitrate compared to controls [8] and infusion 
Table I: Characteristics of participants with and without acid regurgitation or heartburn

\begin{tabular}{|c|c|c|c|c|}
\hline & \multicolumn{2}{|c|}{ Acid regurgitation, $\mathrm{n}(\%)$} & \multicolumn{2}{|c|}{ Heartburn, n (\%) } \\
\hline & No & Yes & No & Yes \\
\hline All participants & $4161(98.4)$ & $66(1.6)$ & $4120(97.5)$ & $107(2.5)$ \\
\hline Males & $1985(47.7)$ & $23(36.5)$ & $1952(47.4)$ & $57(53.3)$ \\
\hline Mean age (SD) & $45.6(8.9)$ & $45.4(9.3)$ & $45.5(9.0)$ & $47.5(8.5)$ \\
\hline Receiving antihypertensives & $255(6.1)$ & $3(4.6)$ & $255(6.1)$ & $3(2.8)$ \\
\hline Mean BMI (SD) & $26.7(4.4)$ & $28.8(4.6)$ & $26.8(4.4)$ & $28.9(5.2)$ \\
\hline \multicolumn{5}{|l|}{ Cigarettes } \\
\hline Never & $2204(53.0)$ & $31(47.0)$ & $2183(53.0)$ & $52(48.6)$ \\
\hline Ever & $987(23.7)$ & $8(12.1)$ & $976(23.7)$ & $19(17.8)$ \\
\hline Current, $<20 /$ day & $597(14.4)$ & $8(12.1)$ & $589(14.3)$ & $16(15.0)$ \\
\hline Current, $=20 /$ day & $373(9.0)$ & $19(28.8)$ & $372(9.0)$ & $20(18.7)$ \\
\hline \multicolumn{5}{|l|}{ Alcohol (units/wk) } \\
\hline None & $659(15.8)$ & $20(30.3)$ & $651(15.8)$ & $28(26.2)$ \\
\hline $1-9$ & $1966(47.2)$ & $26(39.4)$ & $1955(47.4)$ & $37(34.6)$ \\
\hline $10-19$ & $883(21.2)$ & $10(15.2)$ & $877(21.3)$ & $16(15.0)$ \\
\hline$\geq 20$ & $653(15.7)$ & $10(15.2)$ & $637(15.5)$ & $26(24.3)$ \\
\hline \multicolumn{5}{|l|}{ Coffee (cups/day) } \\
\hline None & 801 (19.2) & $20(30.3)$ & $792(19.2)$ & $29(27.1)$ \\
\hline $1-4$ & $2209(53.1)$ & $28(42.4)$ & $2182(53.0)$ & $55(5 \mathrm{I} .4)$ \\
\hline$\geq 5$ & $|15|(27.7)$ & $18(27.3)$ & II 46 (27.8) & $23(2 \mid .5)$ \\
\hline Non- manual social class & $2667(64.1)$ & $44(66.7)$ & $2653(64.4)$ & $58(54.2)$ \\
\hline Mean systolic BP (SD) & $119.8(21.7)$ & $119.2(19.4)$ & $119.8(21.8)$ & $121.0(16.2)$ \\
\hline Mean diastolic BP (SD) & $75.6(19.2)$ & $75.1(10.6)$ & $75.6(19.3)$ & $76.4(12.0)$ \\
\hline
\end{tabular}

Data shown relate to 4227 participants with complete data

of a NO synthase blocker has been seen to induce both raised resting LOS tone and, in keeping with the well known vasodilatory effects of NO, raised blood pressure [9].

\section{Conclusion}

We suggest that factors influencing the endogenous production of NO underlie the observed association between symptoms of gastro-oesophageal reflux and blood pressure. Confirmation of these findings, and further investigation of the pathophysiological role that NO may play in gastro-oesophageal reflux, and possibly Barrett's oesophagus, are warranted.

\section{Competing interests}

The author(s) declare that they have no competing interests.

\section{Authors' contributions}

$\mathrm{LM}$, and $\mathrm{RH}$ were involved in planning and obtaining funding for the Bristol Helicobacter project. JAL managed the project. LM proposed the hypothesis for this paper. LM and PMcC carried out the analyses and wrote the initial draft of the paper. All the authors commented critically on the initial draft, and contributed to the final version of the paper. LM is the guarantor.

Table 2: Association between blood pressure and frequency of acid regurgitation and heartburn

\begin{tabular}{|c|c|c|c|c|c|}
\hline \multirow[t]{2}{*}{ Symptom, frequency } & \multirow[t]{2}{*}{$\mathrm{n}^{\prime}$} & \multicolumn{2}{|c|}{$\begin{array}{l}\text { Mean difference in systolic blood pressure }(\mathrm{mm} \mathrm{Hg})(95 \% \\
\mathrm{Cl}), \mathrm{P}\end{array}$} & \multicolumn{2}{|c|}{$\begin{array}{l}\text { Mean difference in diastolic blood pressure }(\mathrm{mm} \mathrm{Hg}) \\
(95 \% \mathrm{Cl}), \mathrm{P}\end{array}$} \\
\hline & & Age and sex adjusted & Fully-adjusted ${ }^{2}$ & Age and sex adjusted & Fully-adjusted ${ }^{2}$ \\
\hline \multicolumn{6}{|l|}{ Acid regurgitation } \\
\hline Daily & 63 & $-2.5(-4.2$ to -0.8$), 0.012$ & $-4.2(-7.0$ to -1.5$), 0.009$ & $-0.9(-2.9$ to 1.2$), 0.34$ & $-2.1(-4.3$ to 0.0$), 0.053$ \\
\hline Less frequently & 3906 & 1.00 (reference group) & 1.00 & 1.00 & 1.00 \\
\hline \multicolumn{6}{|l|}{ Heartburn } \\
\hline Daily & 104 & 1.7 (-3.7 to 7.1$), 0.48$ & -0.5 (-6.8 to 5.8$), 0.85$ & $-0.6(-1.3$ to 2.5$), 0.46$ & $-0.9(-2.8$ to 1.1$), 0.32$ \\
\hline Less frequently & 3865 & 1.00 & 1.00 & 1.00 & 1.00 \\
\hline
\end{tabular}

I Number of participants for whom full data available

${ }^{2}$ Adjustment for age, sex, BMI, antihypertensive medication, smoking, coffee and alcohol intake, and social class 


\section{Acknowledgements}

We thank the participants in the Bristol Helicobacter Project and the general practitioners and Health Centre staff; the nursing team of Lynne Bradshaw, Julie Watson, Tina Critchley, Jo Lee, Carol Everson-Coombe, Penny Nettlefield and Joanne Smith; Judy Millward, Helen Davies, Amy Hawkins and Sarah Pike for secretarial support and Erwin Brown, Paul Thomas, Nick Pope and Phil Hedges of the Microbiology Department and Peter Spurr, Martin Bullock and Fiona Greenwood of the Pharmacy Department, Frenchay Hospital, for help with the 10,537 breath tests.

Funding: This study was funded jointly by the South and West Regional Research and Development Directorate and GlaxoSmithKline UK. The Department of Social Medicine is the lead centre for the MRC Health Services Research Collaboration.

\section{References}

I. Anderson LA, Murray LJ, Murphy SJ, Fitzpatrick DA, Johnston BT, Watson RG, McCarron P, Gavin AT: Mortality in Barrett's oesophagus:results from a population based study. Gut 2003, 52: $1081-4$.

2. Bateman DN, Colin-Jones D, Hartz S, Langman M, Logan RF, Mant J, Murphy M, Paterson KR, Rowsell R, Thomas S, Vessey M, SURVEIL (Study of Undetected Reactions, Vigilance Enquiry into Links) Group: Mortality study of 18,000 patients treated with omeprazole. Gut 2003, 52(7):942-6.

3. Kennedy T, Jones R: The prevalence of gastro-oesophageal reflux symptoms in a UK population and the consultation behaviour of patients with these symptoms. Aliment Pharmacol Ther 2000, 14:1589-94.

4. Carlsson R, Dent J, Bolling-Sternevald E, Johnsson F, Junghard O, Lauritsen K, Riley S, Lundell L: The usefulness of astructured questionnaire in the assessment of symptomatic gastroesophageal reflux disease. Scand J Gastroenterol 1998, 33:1023-9.

5. Campo SM, Capria A, Antonucci F, Martino G, Ciamei A, Rossini PM, Bologna E, Cannata D: Decreased sympathetic inhibition in gastroeosphageal reflux disease. Clinical Autonomic Research 200I, | |:45-5 |.

6. Bredt DS: Endogenous nitric oxide synthesis: biological functions and pathophysiology. Free Radical Research 1999, 3 I:577-90.

7. Tomita R, Tanjoh K, Fujisaki S, Fukuzawa M: Physiological studies on nitric oxide in the lower esophageal sphincter of patients with reflux esophagitis. Hepatogastroenterology 2003, 50: I I0-4.

8. Kassim SK, El Touny M, El Guinaidy M, El Moghni MA, El Mohsen AA: Serum nitrates and vasoactive intestinal peptide in patientswith gastroesophageal reflux disease. Clin Biochem 2002, 35:64I-6.

9. Konturek JW, Thor P, Lukaszyk A, Gabryelewicz A, Konturek SJ, Domschke W: Endogenous nitric oxide in the control of esophageal motility in humans. J Physiol Pharmacol 1997, 48:20I-9.

\section{Pre-publication history}

The pre-publication history for this paper can be accessed here:

http://www.biomedcentral.com/1471-230X/8/10/pre pub

\section{Publish with Biomed Central and every scientist can read your work free of charge}

"BioMed Central will be the most significant development for disseminating the results of biomedical research in our lifetime. "

Sir Paul Nurse, Cancer Research UK

Your research papers will be:

- available free of charge to the entire biomedical community

- peer reviewed and published immediately upon acceptance

- cited in PubMed and archived on PubMed Central

- yours - you keep the copyright

Submit your manuscript here:

http://www.biomedcentral.com/info/publishing_adv.asp
BioMedcentral 